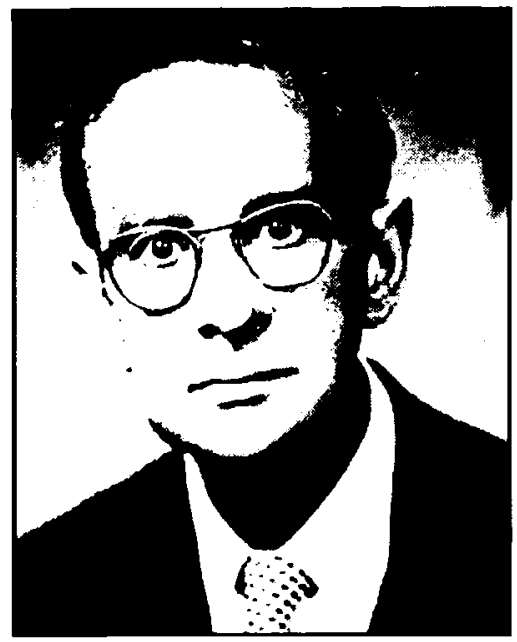

IN MEMORIAM

\title{
RUBENS DE LACERDA MANNA
}

(1914-1995)

A Neuropsiquiatria Brasileira e particularmente a Paranaense perdeu, em 30 de maio de 1995, um de seus ilustres membros - a morte levou Rubens de Lacerda Manna.

Nascendo em 29 de janeiro de 1914 na cidade do Rio de Janeiro era um paranaense de coração, pois aqui morou nos seus últimos $\mathbf{5 0}$ anos. Fez sua formação básica na Rio de Janeiro onde também diplomou-se como médico em 1936, na Faculdade de Medicina da Universidade do Brasil, hoje UFRJ.

Abraçou cedo a carreira militar sendo nomeado em 1938 tenente médico. Serviu e casou-se em 1939 na cidade de Paranaguá com Maria Amazonas Penido Monteiro, tendo três filhas: Maria Margarida, Maria da Glória e Maria Júlia. Também como militar morou em Rio Negro, Lapa e desde 1950 em Curitiba.

Rubens de Lacerda Manna foi expedicionário, tendo servido em 1944 como tenente médico em Livorno na Itália, onde trabalhava como chefe do serviço de Neuropsiquiatria da Seç̧āo Brasileira de Hospitalizações, no 7o. Hospital Militar Norte Americano. Neste período foi distinguido com várias dignidades e honrarias, recebendo elogios, diplomas e medalhas de guerra. Em 1965 foi designado General-Médico do Exército Brasileiro.

Como profissional médico, pertenceu a várias associações médicas nacionais e paranaenses de Neurologia e Psiquiatria. Distinguiu-se como Presidente da Academia Brasileira de Neurologia, no período de 1978-1980, quando foi Presidente do Congresso Brasileiro de Neurologia, realizado em Curitiba.

Na área acadêmica, em 1943 foi nomeado lo. Assistente da Cadeira de Neurologia da Universidade Federal do Paraná (UFPR) no Serviço do Prof. Octavio da Silveira. Foi Docente Livre de Neurologia (1944) e de Psiquiatria (1951). Em 1966 foi designado Professor Adjunto de Neurologia e em 1970, declarado Professor Titular de Neurologia da UFPR. Encerrou suas atividades acadêmicas em 1985 como Chefe do Serviço de Neurologia do Hospital de Clínicas da UFPR. Foi também Professor de Psiquiatria da Faculdade de Medicina da PUC-PR.

$\mathrm{Na}$ atividade científica também teve destaque com vários trabalhos e conferências, especialmente a descrição do primeiro caso de neurocisticercose no Paraná (1945) e a publicação do livro "Alguns aspectos da Psiquiatria Militar" (1950).

Era uma apreciador de línguas estrangeiras dominando o inglês, francês, alemão e italiano, que muito o ajudaram nas sua carreira acadêmica e militar.

Atuou em vários hospitais onde se distinguiu, como no Hospital Psiquiátrico Nossa Senhora da Glória (co-fundador com Octavio da Silveira), Hospital Psiquiátrico Nossa Senhora da Luz (vice diretor) e Diretor do Hospital Geral (militar) de Curitiba.

Sua maior característica na atividade acadêmica e profissional era a aglutinação de colegas. Marcou sua vida pela retidão de caráter, cumprimento do dever e dignidade profissional.

Rubens de Lacerda Manna deixa-nos com saudades. Foi um homem bom. 